\title{
Individualized Treatment for a Rectourethral Fistula: Rare Complications
}

\author{
In Ja Park \\ Department of Colon and Rectal Surgery, Asan Medical Center, University of Ulsan College of Medicine, Seoul, Korea
}

\section{See Article on Page 35-41}

Most rectourethral fistulas (RUFs) are associated with prostate cancer treatment. Historically, such fistulas occur as a result of complications after a radical or transurethral prostatectomy. However, they are also caused by cancer, infection, inflammation or trauma. Over the past 20 years, treatment of prostate cancer, as well as rectal cancer, has changed; today, multimodality treatment, including radiation therapy, has been established as one of the standard treatments. The history of radiation therapy for prostate or rectal cancer is often associated with rectourethral fistulas. Up to $3 \%$ of patients undergoing these kinds of therapies will develop RUFs [1]. Spontaneous healing of such RUFs is rare, and a variety of surgical options have been described, but RUFs can still be extremely challenging to treat. In addition, multiple surgical repairs are often required to heal these types of fistulas.

A transperineal repair, which can provide optimal exposure, is a good initial approach to treating both simple and complex RUFs. It would obtain a successful closure rate of up to $90 \%$, regardless of the addition of radiation therapy. Alternatively, a transsphincteric approach can be considered, with closures rates of $85 \%$ to $88 \%$, but generally in nonirradiated patients [2].

For some cases involving radiation-induced, large, and fibrotic RUFs, muscle flaps are required. The Gracilis muscle is most commonly used for transperineal approaches to buttress the repair. Transabdominal and abdominoperineal repairs are often performed in irradiated patients and are generally reserved for

Correspondence to: In Ja Park, M.D.

Department of Colon and Rectal Surgery, Asan Medical Center, University of Ulsan College of Medicine, 88 Olympic-ro 43-gil, Songpa-gu,

Seoul 135-710, Korea

Tel: +82-2-3010-3937, Fax: +82-2-474-6027

E-mail: ipark@amc.seoul.kr

(C) 2014 The Korean Society of Coloproctology

This is an open-access article distributed under the terms of the Creative Commons Attribution NonCommercial License (http://creativecommons.org/licenses/by-nc/3.0) which permits unrestricted noncommercial use, distribution, and reproduction in any medium, provided the original work is properly cited. extensive resections that may result in permanent fecal diversion and/or urinary diversion because of nonfunctional fecal and urinary systems [3].

Because of the relative rarity of the fistula, as well as technical challenges inherent in successful repair, most series include very few patients, and authors have often applied heterogeneous therapeutic options with mixed postoperative results. The varying descriptions of RUF repairs, the small patient numbers, and the inconsistent reporting of outcomes preclude objective comparisons.

Choi et al. [4] described their personal experience with the treatment for six patients with RUFs. Although patients were heterogeneous in etiology and treatment, as in other studies, the study is worthwhile because the authors showed results of treatment according to surgical options for this rare complication. The authors introduced surgical methods by using figures, which was useful. A comprehensive review of treatment methods, their results, and their indications based on previous reports, in addition to personal experience, would be worthwhile.

The numerous surgical repairs, including those used in this study, highlight the variability in surgeon preference and technical expertise, as well as the need for individualized plans based on patient-specific anatomic and functional characteristics. In addition, collaboration between colorectal and urologic surgeons has to be considered for successful management. Successful RUF closure can be achieved through individualized therapy based on the etiology, the severity and the recurrence status of the RUF.

\section{REFERENCES}

1. Elliott SP, McAninch JW, Chi T, Doyle SM, Master VA. Management of severe urethral complications of prostate cancer therapy. J Urol 2006;176(6 Pt 1):2508-13.

2. Kasraeian A, Rozet F, Cathelineau X, Barret E, Galiano M, Vallancien G. Modified York-Mason technique for repair of iatrogenic rectourinary fistula: the montsouris experience. J Urol 2009;181: 1178-83.

3. Wexner SD, Ruiz DE, Genua J, Nogueras JJ, Weiss EG, Zmora O. Gracilis muscle interposition for the treatment of rectourethral, 


\section{Coloproctology}

rectovaginal, and pouch-vaginal fistulas: results in 53 patients. Ann Surg 2008;248:39-43.

4. Choi JH, Jeon BG, Choi SG, Han EC, Ha HK, Oh HK, et al. Rec- tourethral fistula: systemic review of and experiences with various surgical treatment methods. Ann Coloproctol 2014;30:35-41. 